University of Nebraska - Lincoln

DigitalCommons@University of Nebraska - Lincoln

USDA National Wildlife Research Center - Staff Publications
U.S. Department of Agriculture: Animal and Plant Health Inspection Service

2009

\title{
Effects of a synthetic gonadotrophin-releasing hormone agonist, leuprolide, on rut-associated events in male red deer
}

\author{
G. K. Barrell \\ Faculty of Agriculture and Life Sciences, PO Box 84, Lincoln University, Lincoln 7647, New Zealand, \\ graham.barrell@lincoln.ac.nz \\ S. C. T. Schaafsma \\ Faculty of Agriculture and Life Sciences, Lincoln University, Lincoln, New Zealand \\ M. J. Ridgway \\ Faculty of Agriculture and Life Sciences, PO Box 84, Lincoln University, Lincoln 7647, New Zealand \\ M. Wellby \\ Faculty of Agriculture and Life Sciences, PO Box 84, Lincoln University, Lincoln 7647, New Zealand \\ L. A. Miller \\ USDA-APHIS-Wildlife Services
}

Follow this and additional works at: https://digitalcommons.unl.edu/icwdm_usdanwrc

Part of the Environmental Sciences Commons

Barrell, G. K.; Schaafsma, S. C. T.; Ridgway, M. J.; Wellby, M.; and Miller, L. A., "Effects of a synthetic gonadotrophin-releasing hormone agonist, leuprolide, on rut-associated events in male red deer" (2009). USDA National Wildlife Research Center - Staff Publications. 866.

https://digitalcommons.unl.edu/icwdm_usdanwrc/866

This Article is brought to you for free and open access by the U.S. Department of Agriculture: Animal and Plant Health Inspection Service at DigitalCommons@University of Nebraska - Lincoln. It has been accepted for inclusion in USDA National Wildlife Research Center - Staff Publications by an authorized administrator of DigitalCommons@University of Nebraska - Lincoln. 


\title{
Effects of a synthetic gonadotrophin-releasing hormone agonist, leuprolide, on rut-associated events in male red deer
}

\author{
G. K. Barrell ${ }^{\mathrm{A}, \mathrm{C}}$, S. C. T. Schaafsma ${ }^{\mathrm{A}}$, M. J. Ridgway ${ }^{\mathrm{A}}$, M. Wellby ${ }^{\mathrm{A}}$ and L. A. Miller ${ }^{\mathrm{B}}$

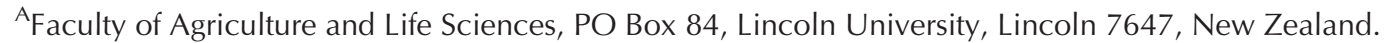 \\ ${ }^{B}$ Product Development Research Program, USDA APHIS WS National Wildlife Research Center, \\ 4101 LaPorte Avenue, Fort Collins, CO 80521, USA. \\ ${ }^{\mathrm{C} C o r r e s p o n d i n g ~ a u t h o r . ~ E m a i l: ~ g r a h a m . b a r r e l l @ l i n c o l n . a c . n z ~}$
}

\begin{abstract}
This study examined the effectiveness of leuprolide, a gonadotrophin-releasing hormone agonist, in suppressing rut-associated events in farmed male red deer. In mid-January ( 6 weeks before the rut period in the southern hemisphere) adult red deer (Cervus elaphus scoticus) stags that had been allocated to three groups ( $n=10$ per group) received leuprolide, administered subcutaneously in a 90-day release formulation, at zero (control), low (22.5 mg) or high (45 mg) doses. Following treatment with leuprolide there was evidence of suppression of mean plasma luteinising hormone concentration that was significant $(P<0.05)$ at 9 weeks. Mean plasma testosterone concentration of all three groups rose following treatment, then declined prematurely in the low- and high-dose leuprolide-treated groups, so that it was significantly $(P<0.05)$ suppressed $\left(0.66 \pm 0.29\right.$ and $2.0 \pm 0.88 \mathrm{ng} \mathrm{mL}^{-1}$, low and high dose respectively) in early April when the peak value $\left(9.0 \pm 1.94 \mathrm{ng} \mathrm{mL}^{-1}\right)$ was recorded from control stags. A reduction in mean liveweight occurred in all three groups through February-April and this did not differ among treatments. However, a corresponding reduction in mean body condition score was greater in the control stags $(P<0.05)$. There was little effect of leuprolide treatment on aggressive behaviours, but it lowered roaring frequency in the latter period of the rut. The results indicate that this gonadotrophinreleasing hormone agonist has potential for application in the deer farming industry to suppress undesirable effects of the rut.
\end{abstract}

Additional keywords: agonistic behaviour, contraception, luteinising hormone, liveweight, testosterone, rut.

\section{Introduction}

In the deer farming sector there are concerns about aggressive behaviour and losses of liveweight of stags during the rut period, and, in regions of the world where deer are becoming overabundant, there is a call for humane methods of fertility control to manage populations of wild deer. In both of these situations it is likely that use of chemical agents that suppress reproductive function in deer stags will become an important management tool. Two major approaches to achieve such control of reproductive function in male mammals are use of vaccines raised against gonadotrophin-releasing hormone $(\mathrm{GnRH})$ to achieve immunocastration, and use of GnRH agonists to modify function of the pituitary gland and, thus, disrupt the reproductive control axis (Padula 2005; Trigg et al. 2006). Immunisation of red deer (Cervus elaphus scoticus) stags against GnRH has been used with variable success in adult (Lincoln et al. 1982; Barrell et al. 2002) and immature (Freudenberger et al. 1993) red deer males, as well as in white-tailed bucks (Odocoileus virginianus, Miller et al. 2000). In the case of GnRH agonists, Lincoln (1987) showed stimulation of reproductive function in red deer stags following an infusion of buserelin. This result indicated a stimulatory action of buserelin, but the effects of other GnRH agonists could be inhibitory, and, thus, the potential of any single compound to inhibit reproduction should be investigated on an individual basis. An alternative approach is the use of contraceptive steroids.
Studies with deer have demonstrated some success in suppression of male reproductive activity with synthetic progestagens such as melengestrol acetate (fallow deer Dama dama, Wilson et al. 2002) and medroxy progesterone acetate (red deer, Muir et al. 1982).

However, as well as being dependent on their mode of action on the reproductive axis, much of the potential for use of chemical agents rests on their mechanism of delivery. Recent advances in development of biodegradable implants containing GnRH agonists have led to sustained-release delivery systems that have provided long-term contraceptive effects in heifers and cows following use of implants containing deslorelin (D'Occhio et al. 2002). In deer, biodegradable implants containing leuprolide, another $\mathrm{GnRH}$ agonist, have successfully generated reversible long-term contraception in wapiti (Cervus elaphus) females (Baker et al. 2002, 2005; Conner et al. 2007). The present study was conducted to determine whether such implants containing leuprolide would mitigate negative effects of the rut on liveweight and body condition in red deer males - another subspecies of Cervus elaphus.

\section{Materials and methods}

Animals

Thirty adult ( $\geq 5$ years old) red deer (Cervus elaphus scoticus) stags were managed as three separate experimental groups on 
three adjacent paddocks grazing pasture comprising mainly perennial ryegrass and white clover with water available ad libitum at the Research Farm, Lincoln University, in Canterbury, New Zealand $\left(43^{\circ} 38^{\prime} 60 \mathrm{~S}, 172^{\circ} 28^{\prime} 60 \mathrm{E}\right)$. The groups were interchanged among the three paddocks each week. All procedures used in the study were conducted with approval from the Lincoln University Animal Ethics Committee.

\section{Experimental procedure}

Stags were allocated to one of three treatment groups $(n=10$ per group) as follows: controls (zero dose leuprolide, i.e. glycine in Atrigel), low-dose leuprolide (22.5 mg leuprolide acetate in Atrigel) or high-dose leuprolide (45 mg leuprolide acetate in Atrigel, previously shown to be highly effective in wapiti females, Baker et al. 2002). Leuprolide was provided as lyophilised leuprolide acetate (D-Leu ${ }^{6}-\mathrm{GnRH}-\mathrm{Pro}^{9}$-ethylamide acetate) powder in $22.5-\mathrm{mg}$ aliquots. The 90-day slow-release formulation was prepared by mixing each leuprolide powder aliquot with $1 \mathrm{~mL}$ of Atrigel (Atrix Laboratories, Fort Collins, $\mathrm{CO}, \mathrm{USA}$ ) in a syringe immediately before s.c. injection into the neck of each stag at the start of the trial, in January (mid-summer).

For handling procedures, stags were mustered every 3 weeks from their paddocks into a barn where they were placed singly into a padded side-loading crush. Liveweight, scrotal diameter (anterior-posterior distance at equator of scrotal mass measured by vernier caliper) and body condition score (scored 1 to 5 , where 1 is very lean, 5 is fat, Audigé et al. 1998) were recorded and a single blood sample $(10 \mathrm{~mL})$ was obtained via jugular venipuncture into a heparinised evacuated glass container. Blood samples were centrifuged for $10 \mathrm{~min}(1000 g)$ within $1 \mathrm{~h}$ of collection and the resultant plasma was stored frozen $\left(-20^{\circ} \mathrm{C}\right)$. Antler growth was monitored by visual appraisal.

\section{Behavioural observations}

Behavioural observations were conducted from 0830 to 0930 hours and from 1545 to 1645 hours each day for 28 days (late April to late May) during the rut period. The animals were observed from a tower that concealed the observer but enabled monitoring of all three groups during the same period. A focal sampling technique was used to record the occurrence of the following behaviours: chasing, roaring, fighting, displaying, pacing, rubbing, wallowing and riding. This involved observation of a focal group of animals and recording behaviours of all individuals in the focal group. Frequency was determined as the total of the number of observations recorded every $5 \mathrm{~min}$ for the 120-min observation period each day. In addition to the focal sampling, the number of animals that were active, standing, resting and grazing was recorded every five minutes. The data from every 7 days were pooled to produce weekly means.

\section{Hormone radioimmunoassay}

Plasma luteinising hormone ( $\mathrm{LH})$ concentration was measured in duplicate $100-\mu \mathrm{L}$ aliquots, using a heterologous, double-antibody radioimmunoassay. The iodinated tracer and the reference preparation were prepared by using purified ovine $\mathrm{LH}$ (NIDDK-oLH-I-2, no. AFP7071B). Standards were prepared by dissolving the reference LH in low-LH cervine plasma obtained from hinds treated with medroxyprogesterone acetate (Promone E, Upjohn Inter-American Corp., Auckland, NZ). The primary antiserum (NIDDK anti-o-LH1, AFP192 279), raised in a rabbit against highly purified ovine LH, was used at a dilution of $1: 250000$. Specificity of the primary antiserum, expressed in terms of cross-reactivity with pituitary hormones other than LH, has been established (by NIDDK and in sheep) to be $5.4 \%$ for ovine $\mathrm{FSH}, 0.6 \%$ for ovine growth hormone, $0.1 \%$ for ovine thyroid stimulating hormone, and $<0.01 \%$ for ovine prolactin, arginine, vasopressin and adrenocorticotrophic hormone. A suspension of cellulose coated with anti rabbit gamma globulin antibody (Sac-cel, AA-SAC1, IDS, Boldon, UK) was used to precipitate bound tracer. Samples with count differences greater than $10 \%$ were repeated. The LH measurements were carried out over three assays. Intra-assay $\mathrm{Cvv}$. at $5.3 \mathrm{ng} \mathrm{mL}^{-1}$ were $10.9,11.1$, and $10.7 \%$, respectively, and inter-assay CV. was $11.8 \%$ for plasma pools displacing radio-labelled LH to, respectively, 35.1, 33.7 and $32.1 \%$ of the total bound. Because ovine LH was used for the standard source in this assay, results are strictly ovine LH equivalents. For simplicity they are expressed here as ng LH.

Plasma testosterone concentration was measured by direct radioimmunoassay (Garnier et al. 1978) using a non-extracted technique described by Schanbacher and D'Occhio (1982). This assay used $\left[1,2,6,7, \mathrm{H}^{3}\right]$ testosterone (TRK 402, Amersham, Little Chalfont, Buckinghamshire, UK) as tracer and rabbit-antitestosterone-11-bovine serum albumin serum (\#250, supplied by GD Niswender, Colorado State University, Fort Collins,

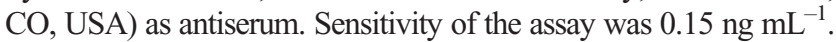
Intra-assay coefficients of variation (CV) were 16, 9.6, and $8.5 \%$. The percentages bound were, respectively, 54, 29 and $68 \%$. Inter-assay CV was $16.6 \%$. Serially diluted deer plasma exhibited parallel binding to that of the standard curve (Shi and Barrell 1992).

\section{Statistical analyses}

Data for plasma $\mathrm{LH}$ and testosterone and concentrations, liveweight, scrotal diameter and the behavioural records were analysed by using SPSS (Statistical Package for Social Sciences, version 12.0, SPSS, Chicago, IL, USA). Hormonal data were transformed to their logarithm (base 10) before analysis.

For transformed plasma LH and testosterone concentrations and for scrotal diameter and liveweight, a 1-way ANOVA with a post hoc Scheffé analysis was used to compare differences between groups. Body condition score and behavioural observations were analysed using two non-parametrical tests (Kruskall-Wallis and Mann-Whitney $U$ ). The influence of treatment on body condition score and agonistic behaviour during the trial was examined by a post hoc Scheffé analysis. Results are presented as the mean \pm s.e.

\section{Results}

Liveweight and body condition score

Mean liveweight of each group of stags (Fig. 1) tended to peak in late summer (February), decline during autumn (March, April) and remain low during winter (May, June). There was no detectable effect of leuprolide treatment on 
mean liveweight during the trial. Mean body condition scores were lower in April than in December $(P<0.01)$, but increased slightly $(P<0.01)$ between April and June (Fig. 2). Throughout the study, leuprolide-treated stags had higher $(P<0.05)$ mean body conditions scores than control animals.

\section{Scrotal diameter}

Overall mean $(n=30)$ scrotal diameter tended to increase during summer (from $4.6 \pm 0.21$ to $5.4 \pm 0.22 \mathrm{~cm}$ ) and decline in autumn, reaching $4.5 \pm 0.19 \mathrm{~cm}$ in May. There was a trend $(0.05<P<0.1)$ for leuprolide-treated groups to have

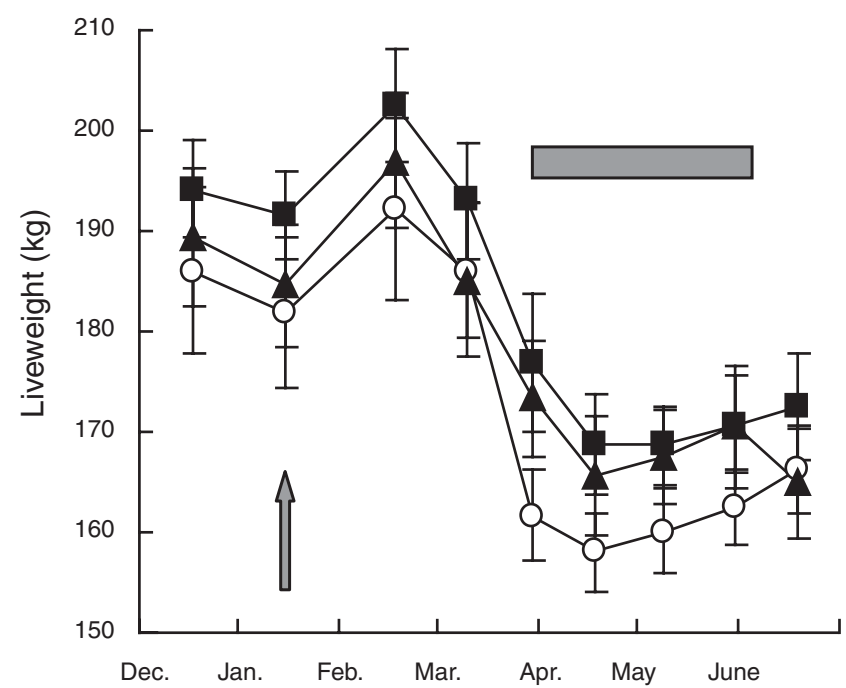

Fig. 1. Mean liveweight of red deer stags ( $n=10$ per group) treated (at arrow) with low dose (22.5 mg, $\mathbf{\Delta})$, high dose ( $45 \mathrm{mg}, \boldsymbol{\square})$ leuprolide implants or vehicle-only implants (controls, $\bigcirc$ ) in January (mid-summer). Data were recorded approximately monthly from December until June. The horizontal bar indicates approximate duration of the rut. Vertical bars denote s.e.

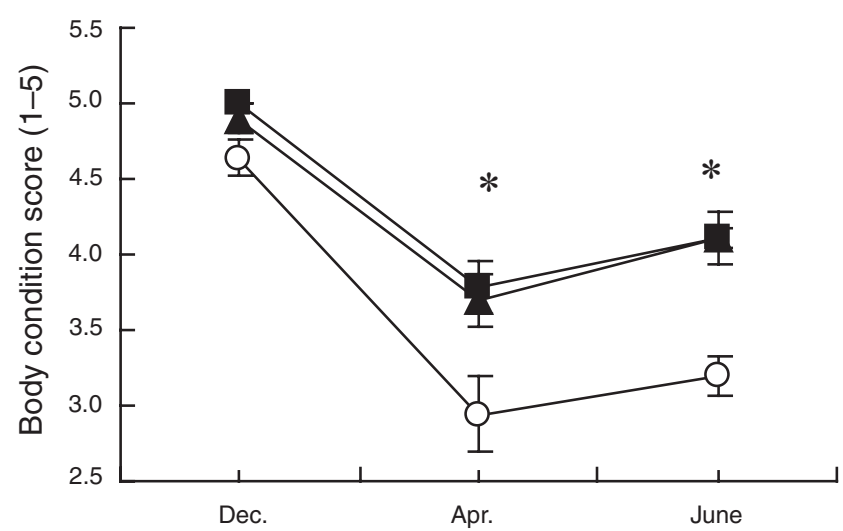

Fig. 2. Mean body condition score of red deer stags ( $n=10$ per group) treated with low dose $(22.5 \mathrm{mg}, \boldsymbol{\Delta})$, high dose $(45 \mathrm{mg}, \mathbf{\square})$ leuprolide implants or vehicle-only implants (controls, $\bigcirc$ ) in January (mid-summer). Data were recorded on three occasions between December and June and range from 1 (poor condition) to 5 (fat condition). Vertical bars denote s.e. * Significant difference $(P<0.05)$ between groups. slightly lower mean scrotal diameters than controls during autumn.

\section{Antler growth}

Some stags in the leuprolide-treated groups (three per group) had minor (a few $\mathrm{cm}$ ) antler growth, whereas there was no antler growth in any control group stag during the study period.

\section{LH and testosterone}

Mean plasma concentrations of LH and testosterone tended to increase in late summer (February, March) peak thereafter (March, April), and decline during autumn (April) (Fig. 3). At 9 weeks post treatment, in April, leuprolide-treated groups had lower $(P<0.01)$ mean plasma LH and testosterone concentrations than controls (Fig. 3). In May, mean plasma testosterone concentration was low in all cases although it was higher $(P<0.05)$ in the low leuprolide dose group than in the other two groups.

\section{Behaviour}

The overall incidence of chasing and fighting behaviours declined $(P<0.05)$ with time during the period of observations. Roaring activity (Fig. 4) in control and low-dose groups increased $(P<0.05)$ to the highest level in early May, and there was evidence $(P<0.05)$ of earlier cessation of roaring in the low-dose group. In the high-dose group the
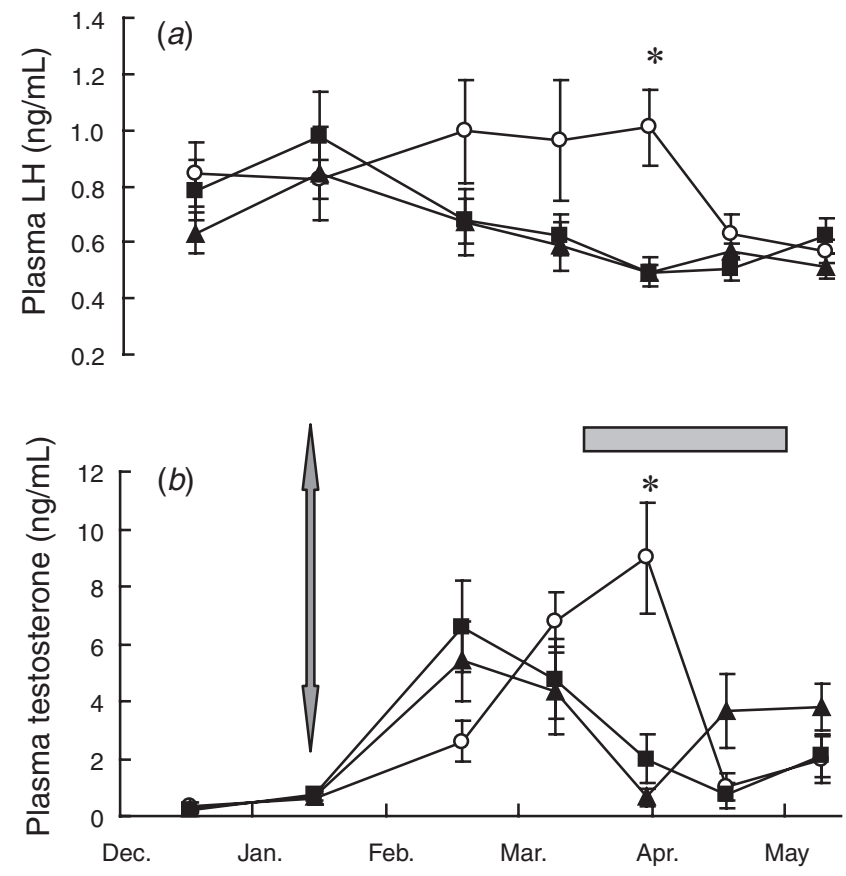

Fig. 3. Mean (a) plasma luteinising hormone (LH), and (b) testosterone concentration of red deer stags ( $n=10$ per group) treated (at arrow) with low dose (22.5 mg, $\mathbf{\Delta})$, high dose ( $45 \mathrm{mg}, \boldsymbol{\square})$ leuprolide implants or vehicle-only implants (controls, $\bigcirc$ ) in January (mid-summer). Data were recorded approximately monthly from December until May. The horizontal bar indicates approximate duration of the rut. Statistics performed after transformation of the data to their $\log _{10}$. Vertical bars denote s.e. *Significant difference $(P<0.05)$ between groups. 


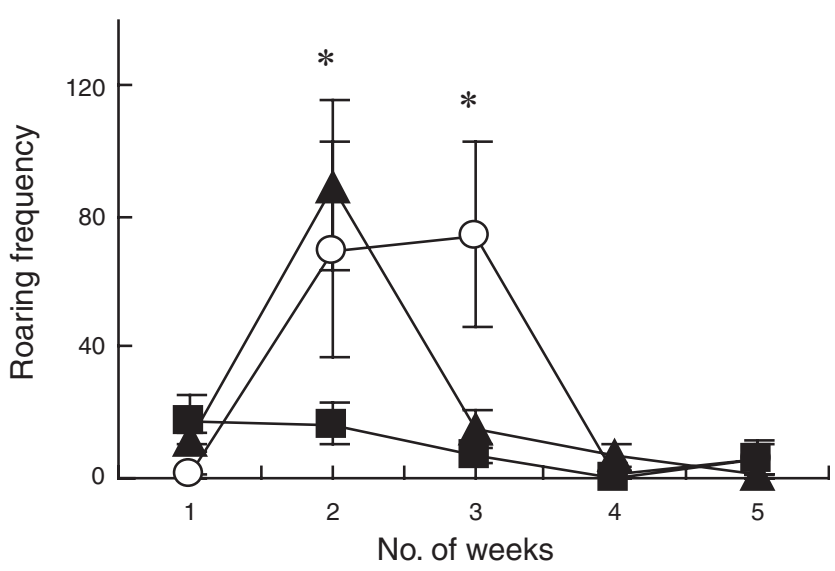

Fig. 4. Weekly mean frequency (see text for definition) of roaring behaviour recorded twice daily for 5 weeks (from 22 April to 28 May) during the rut period of red deer stags ( $n=10$ per group) treated with low-dose $(22.5 \mathrm{mg}, \boldsymbol{\Delta})$ or high-dose (45 mg, $\mathbf{D}$ ) leuprolide implants or vehicle-only implants (controls, $\bigcirc)$ in January (mid-summer). Vertical bars denote s.e. *Significant difference $(P<0.05)$ between groups.

incidence of roaring was low $(P<0.05)$ throughout the observation period (Fig. 4).

\section{Discussion}

The sustained release preparation of leuprolide used here on male deer produced a premature suppression of the rutassociated events. This finding is based on the effects recorded on plasma concentrations of $\mathrm{LH}$ and testosterone and on changes in scrotal diameter and reproduction-related behaviours aggression and roaring. Rut-associated losses in liveweight were not affected by leuprolide but there was some evidence for a treatment-induced amelioration of loss of body condition. The findings show that slow release delivery of the GnRH agonist, leuprolide, has potential as a means for controlling some rut-associated events in farmed male red deer. It is noteworthy that the suppressive effects recorded here were not dramatic, there were only minor effects on reproductive-related behaviours, and leuprolide treatment did not prevent loss of liveweight by stags in autumn. However, it is feasible that higher-dose preparations may be more effective and merit further study. The occurrence of some antler growth, as recorded here, accords with suppression of testosterone secretion (Muir et al. 1988) induced by treatment with leuprolide, but such growth may be regarded by farmers as a nuisance.

In general, these results from use of a sustained-release preparation of leuprolide in male red deer parallel those obtained with their closely related female counterparts, elk also known as wapiti. In this subspecies (Baker et al. 2002, 2005; Conner et al. 2007) leuprolide-treated animals did not become pregnant during the breeding season following treatment. In accord with the present results for males, Baker et al. (2002, 2005) also reported suppression of plasma LH concentration in the females. Also, in concert with results of the studies in females, our observations showed little effect of leuprolide on behaviour of the males. However, we did not attempt to measure libido specifically or to examine whether the stags were willing to mount females.

In the farmed deer sector, rut-associated loss of liveweight and body condition in stags can be regarded as detrimental to productivity and to potential well being of stags. Hence, the indication that leuprolide use was associated with a reduction in severity of the loss of body condition in the lowand high-dose leuprolide-treated stags provides a positive note for application of this technology on commercial farms. This finding contrasts with the winter-time loss of body fat composition of leuprolide-treated hinds, compared with pregnant controls (Conner et al. 2007). However, those authors were unable to explain this unexpected result, and it is likely that the possible benefit of agonist treatment on body condition of stags, as indicated in the present results, will endure in further studies.

Another concern for farmers is aggressiveness in the behaviour of rutting stags. However, the behavioural observations recorded here show little evidence that this aspect was affected by leuprolide, although there was some treatmentrelated suppression of roaring activity. During the observation periods, the stags spent a high proportion of the time grazing (up to $70 \%$ of the time) or resting (up to $60 \%$ of the time) and there was comparatively little aggressive behaviour. It is, thus, not possible to reach any firm conclusion about this aspect of stag behaviour in relation to the treatment.

In spite of some practical limitations, as pointed out by Conner et al. (2007), the present findings show that sustained delivery preparations containing GnRH agonists have promise as acceptable agents for the reproductive manipulation of farmed deer.

\section{References}

Audigé L, Wilson PR, Morris RS (1998) A body condition score and its use for farmed red deer hinds. New Zealand Journal of Agricultural Research 41, 545-553.

Baker DL, Wild MA, Conner MM, Ravivarapu HB, Dunn RL, Nett TM (2002) Effects of GnRH agonist (leuprolide) on reproduction and behavior in female wapiti (Cervus elaphus nelsoni). Reproduction Supplement 60, 155-167.

Baker DL, Wild MA, Hussain MD, Dunn RL, Nett TM (2005) Evaluation of remotely delivered leuprolide acetate as a contraceptive agent in female elk (Cervus elaphus nelsoni). Journal of Wildlife Diseases 41, 758-767.

Barrell GK, Nicol AM, Keeley MJ (2002) An attempt to suppress the rutassociated loss of live weight in stags by immunocastration. Proceedings of the New Zealand Society of Animal Production 62, 149-151.

Conner MM, Baker DL, Wild MA, Powers JG, Hussain MD, Dunn RL, Nett TM (2007) Fertility control in free-ranging elk using gonadotropin-releasing hormone agonist leuprolide: effects on reproduction, behavior, and body condition. Journal of Wildlife Management 71, 2346-2356. doi: 10.2193/2006-463

D'Occhio MJ, Fordyce G, Whyte TR, Jubb TF, Fitzpatrick LA, Cooper NJ, Aspden WJ, Bolam MJ, Trigg TE (2002) Use of GnRH agonist implants for long-term suppression of fertility in extensively managed heifers and cows. Animal Reproduction Science 74, 151-162. doi: 10.1016/S03784320(02)00189-6

Freudenberger DO, Wilson PR, Barry TN, Sun YX, Purchas RW, Trigg TE (1993) Effects of immunization against GnRH upon body growth, voluntary food intake and plasma hormone concentration in yearling red deer stags (Cervus elaphus). Journal of Agricultural Science 121, 381-388. doi: 10.1017/S0021859600085579 
Garnier DH, Cotta Y, Terqui M (1978) Androgen radioimmunoassay in the ram: results of direct plasma testosterone and dehydroepiandrosterone measurement and physiological evaluation. Annales de Biologie Animale, Biochimie, Biophysique 18, 265-281. doi: 10.1051/rnd:19780206

Lincoln GA (1987) Long-term stimulatory effects of a continuous infusion of LHRH agonist on testicular function in male red deer (Cervus elaphus). Journal of Reproduction and Fertility 80, 257-261. doi: 10.1530/ jrf.0.0800257

Lincoln GA, Fraser HM, Fletcher TJ (1982) Antler growth in male red deer (Cervus elaphus) after active immunization against LH-RH. Journal of Reproduction and Fertility 66, 703-708. doi: 10.1530/jrf.0.0660703

Miller LA, Johns BE, Killian GJ (2000) Immunocontraception of whitetailed deer with a GnRH vaccine. American Journal of Reproductive Immunology 44, 266-274. doi: 10.1111/j.8755-8920.2000.440503.x

Muir PD, Barrell GK, Sykes AR (1982) Modification of antler growth in red deer stags by use of a synthetic progestagen. Proceedings of the New Zealand Society of Animal Production 42, 145-147.

Muir PD, Sykes AR, Barrell GK (1988) Changes in blood content and histology during growth of antlers in red deer (Cervus elaphus) and their relationship to plasma testosterone levels. Journal of Anatomy 158, 31-42.

Padula AM (2005) GnRH analogues - agonists and antagonists. Animal Reproduction Science 88, 115-126. doi: 10.1016/j.anireprosci.2005.05.005
Schanbacher BD, D'Occhio MJ (1982) Validation of a direct radioimmunoassay for testosterone in unextracted serum from five species: application to study of the hypothalamic-pituitary-gonadal axis in males. Journal of Andrology 3, 45-51.

Shi ZD, Barrell GK (1992) Requirement of thyroid function for the expression of seasonal reproductive and related changes in red deer (Cervus elaphus) stags. Journal of Reproduction and Fertility 94, 251-259. doi: 10.1530/ jrf.0.0940251

Trigg TE, Doyle AG, Walsh JD, Swangchan-uthai T (2006) A review of advances in the use of the GnRH agonist deslorelin in control of reproduction. Theriogenology $\mathbf{6 6}, \quad 1507-1512$. doi: 10.1016/j. theriogenology.2006.02.037

Wilson TW, Neuendorff DA, Lewis AW, Randel RD (2002) Effect of zeranol or melengestrol acetate (MGA) on testicular and antler development and aggression in farmed fallow bucks. Journal of Animal Science 80, 1433-1441.

Manuscript received 15 May 2009, accepted 15 July 2009 